\title{
Keda Çewres Serran û Yew Kedkaro Bêhempa: M. Malmîsanij û Kitabê ci "Kurmancca İle Karşılaştırmalı Kırmancca (Zazaca) Dilbilgisi”"
}

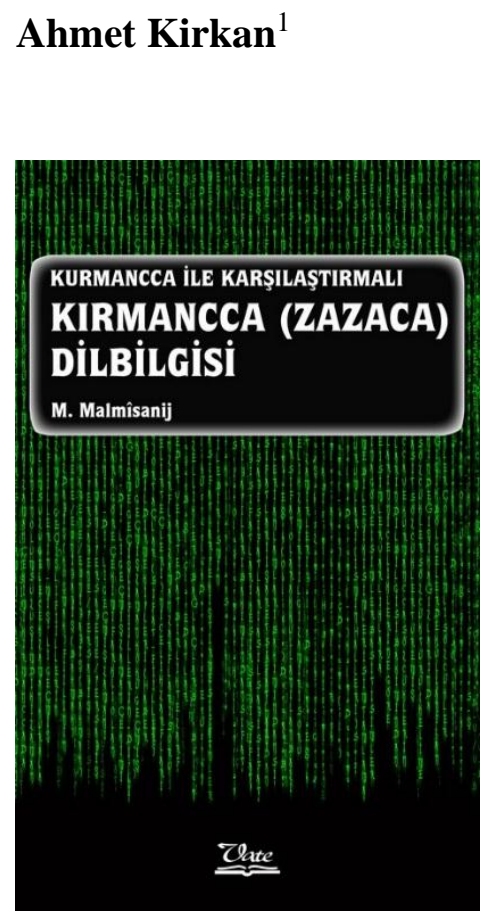

Received: January 4, 2015

Accepted: January 26, 2015

\author{
Nuştox: M. Malmîsanij \\ Weşanxane: Weşanxaneyê Vateyî, 2015 \\ Mijar: Gramer, Gramero Muqaseyî \\ Rîpel: 302 \\ İSBN:978-975-6278-89-5
}

Kitabê Mamosta M. Malmîsanijî keda 40 serre emre ci ya. Çunke yeno zanayene ke kitab nuştene û xususen zî kitabê grameri nuştene zaf çîyêko zehmet o. Ganî ke gramerzan yan nuştoxê gramerî; ziwan û lehçeya xo de xorîn bo, eserê ke o ziwan de ameyê nuştene înan ra xeberdar bo, tarîxê ziwanê xo bizano, lehçeyanê ziwanê xo bizano, lehçeya xo ser o pispor bo, çend hebî ziwanê xerîbî ke ziwanê ci ya têkildar ê bizano. Yanî gramer nuştene bi gramerî ya pîya heme çî ya eleqedar o. Eke no gramer, gramerê kirmanckî (zazakî) bo, gureyê ziwanzanî hîna aloz û zehmet beno. Çunke kirmanckî wayîrê edebîyatêkê nuştekî nîya, eserê nuştekî hîna newe-newe yenê nuştene, fekî û şîweyî zaf ê, her fek xo sey feko bingeyên hesibneno, hetê standardîzasyonî ra şeklêk ke her kesî sey konsensusî qebul kerdo çin o, pîyase de zaf kitabê gramerî estê ûsn. zorîyî karê cigêrayoxî zor kenê. Ganî kes îfade biko ke gramer nuştene seba ziwanî karo tewr bi zehmet û tewr aloz o. Kurdkî de no proses bi şeklêko xerîb cereyan keno. Nuştoxî verê verkan kitabê gramerî nusenê û dima sewbîna eseran nusenê.

Recommended citation:

Kirkan, A. (2016). Keda Çewres Serran Û Yew Kedkaro Bêhempa: M. Malmîsanij Û Kitabê Cı "Kurmancca İle Karşılaştırmalı Kırmancca (Zazaca) Dilbilgisi”'[Review of the book Kurmancca İle Karşılaştırmalı Kırmancca (Zazaca) Dilbilgisi by M. Malmîsanij]. International Journal of Kurdish Studies 2 (1), pp. $105-108$.

\footnotetext{
${ }^{1}$ Research Assistant, Dicle University, PhD Student, Kurdish Language and Culture, Diyarbakır, Turkey, Email: ahmetkirkan@gmail.com
} 
Labelê gramer nuştene karêko zor o. Heta nika Sazgeha Ziwan yê Tirkî tena yew kitabê gramerî neşr kerdo. Çunke eke dîyin, hîrêyin... zî bibo o wext gure têmîyan keweno. Malmîsanijî 40 serre xebata gramerî kerda û dima kitabêk nuşto. Qandê cû ma no kitab weçîna û ney ser o vindertî.

Pîyase de çend hebî kitabê gramerî estê ke nînan ra taye ci bi şeklêko lokal/mehelî ya ameyê nuştene. Nê kitabî xebata folklorî de û xebatanê mehelîyan de cayêkê muhîmî gênê. Labelê kitabê M. Malmîsanijî hetê tedeyî, ûsul, tertîb, îzahat, vatene û kede ra cayêko taybet de yo. Kitab de, Malmîsanijî gramer goreyê qaydeyanê îlmî, bi hawayêko muqayese/pêveronayişî tenzîm kerdo. Lehçeyê kurdkî; kirmanckî û kurmanckî bi delîlanê îlmîyan a muqayese bîyê. Kitab de lehçeyê kirmanckî û kurmanckî hetê fonetik, morfoloji û sentaksî ra ameyê analîzkerdene û peynîya kitabî de yew encam ameyo meydan. Nê encamî de Malmîsanijî goreyê hîsanê xo hereket nêkerdo. Çunke heme çî bi tablo û îstatîstîkan ameyo hesabkerdiş, goreyê îstatîstîkan doneyî vejîyayê meydan û nê doneyan encamêk veto meydan. Kitab hetê tabloyan ra zaf dewlemend o. Hema-hema seba her mijarî tabloyî amade bîyê; kirmanckî û kurmanckî bi tercumeyê tirkî ya deyayo. No seba wendoxan -wendoxê ke perwerdeyê xo bi Tirkî dîyo- fehmkerdişî zaf asan keno. Ziwanê kitabî tirkî yo. No zî hetê Malmîsanijî ra bizanayîş a ameyo tercîhkerdiş û bi eynî çî ya têkildar o. Çunke nuştox qayîl o ke kitabê ey bireso girseyêkê girdî û zaf merdimî kitabî ra îstîfade biko.

Malmîsanij 1952 de yew dewa Pîranî de maya xo ra bî. Wendişê xoyo verên û mîyanên Kurdîstan de, unîversîte Anqara de qedênaya. Dima ey heşt serrî mamostayîye kerda. Serra 1982 de welat ra vejîyayo. Unîversîteya Sorbonne (Parîs) û Unîversîteya Uppsala (Swêd) de qismê ziwananê îranî wendo. Unîversîteya Linköpingî de qismê perwerdeyî de wendo. Swêd de Unîversîteya Goteborgî de masterê xo temam kerdo. Malmîsanij hîna zaf bi lehçeya kirmanckî û tirkî nuseno. Ehmedê Xasî û Usman Efendîyê Babijî ra dima heta serra 1970 welat de kirmanckî nênusîyabî. Malmîsanij keso tewr verên o ke serranê 1970 de welat de kirmanckî nuşto. Ey û tayê embazanê xo 1979-1980 de Tirkîya de kovara Tîrêje vete. Nêmeyê na kovare kirmanckî nêmeyê aye zî kurmanckî (kirdaskî) bî. Ferhengê verênê kirmanckî Malmîsanijî amade kerdo û serra 1987 de neşr kerdo. Ey fariskî û tirkî ra tayê hîkayeyî zî tercumeyê kirmanckî kerdî. Reya verêne ey Mewlidê Ehmedê Xasî û Usman Efendîyê Babijî herfanê erebkî ra çarnayê herfanê latînkî ser û nê her di şaîrê kirmancan ma rê dayê naskerdene. Heta ewro nêzdîyê pancas rojname û kovaran de, bi seyan nuşteyê Malmîsanijî vejîyayê. Ey nê kovaran de redaktorîye kerde: Tîrêj (Îzmîr), Hêvî (Parîs), Armanc (Stockholm), Çarçira (Stockholm), Wan (Stockholm), Çira (Stockholm). O demêk Swêd de serekê Komeleya Nuştoxanê Kurdan bi. Tayê kitabê ey tercumeyê îngilizkî, erebkî, kurdkîya başûrî (soranî) û kurmanckî; tayê şî̂rê ey zî tercumeyê îngilizkî, franskî û swêdkî bîyê. (zazaki.net)

Kitab eslê xo de hîrê beşan ra ware ameyo. Beşê yewin fonolojî ser o yo. Ma zanê ke fonoloji ser o yewna kitabê Malmîsanijî, bi nameyê "Kürtçede Ses Değişimi”" esto. Malmîsanijî nê kitabê xo de fonetîkê kurdkî ser o dergûdila îzahat dayo. Nê beşî de Malmîsanij behsê alfabeyanê kirmanckî keno û alfabeya xo ra behs keno ke Malmîsanij bi xo alfabeya Celadet Alî Bedirxanî şuxulneno. Ma zanê ke seba kirmanckî alfabeyê cîya-cîya yî yenê şuxulnayene. Malmîsanij ney ser o munaqeşe keno û alfabe de herf zêdekerdişî rê îtîraz keno. Malmîsanij fikrê xo wina îfade keno: "Yew ziwan de her vengî bi yew herf a îfade 
kerdene û seba her fekî alfabeyêka cîya viraştene hewce nêkeno. Vengê ke alfabe de ca bigîrê ganî umûmî bê. Her ziwan de no tewir nuansî estê labelê nê alfabe de ca nêgînê. Na rewşe seba heme ziwanan eynî ya" (Malmîsanij 2015: 28-29). Tayê nuştoxî derheqê şuxulnayişê herfa "Ğg" de zaf munaqeşe kenê. Malmîsanijî seba na herfe îstatîstîkêk viraşto û nê doneyî vistê xo dest: " Goreyê di metnê ke ma tedqîq kerdî, mîyanê 15833 herfan de tena 22 hebî

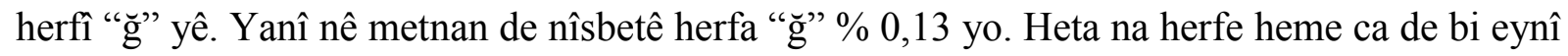
şekl a nîyena telefuz kerdene.”(Malmîsanij 2015: 30). Malmîsanij mabênê kirmanckî û kurmanckî de vurîyayişê vengan bi nimûne û bi tabloyan mojneno. Kirmanckî tena bi kurmanckî ya muqayese nêkeno, kirmanckî xo mîyan de zî muqayese keno û cîyayîyan tesbît keno (Malmîsanij 2015: 36).

Beşê dîyin de nuştox morfolojîyê kirmanckî û kurmanckî ser o bi hawayêko muqayeseyî vindeno. Tîya de taye xususîyetê estê ke ma nînan sewbîna kitabanê gramerî de nêvînenê. Malmîsanij xususen nê beşî de etîmolojîyê çekuyan ser o melumat dano (Malmîsanij 2015: 48,50,89). Reyna Malmîsanij hakimê lehçeyanê kurdkî yo. Aye ra, gama ke delîl ano, sorankî, gorankî, kurmanckî ra şî̂re û nesran ra delîl ano (Malmîsanij 2015: 182183). Malmîsanijî semedê meseleyanê zehmetan xeylêk îzahatê eşkera û sadeyî kerdê. No zî goreyê ma qîymetê kitabî zêdneno. Kitab de çekuyî, nameyî, zemîrî, sifetî, bestoxî, edatî, zerfî, înterjeksîyonî û karî bi sîstemêk a rêze bîyê. Goreyê ma, tîya de zî neweyîyêk esta. Çunke seba kirmanckî babeta tewr aloze û zehmete, karî û antişê karan o. Sewbîna mijaran de pêşnîyazê Grûba Xebate ya Vateyî estê labelê kar û antişê karan ser o hîna konsensus nêvirazîyayo. Seba aye ra no kitab de hîrê paran ra parêke seba babeta karan û antişê karan abirîyaya. Yanî heme hetê karan bi şeklêko sîtematîk û îlmî ameyê îzahkerdene.

Beşê hîrêyin derheqê sentaksî de ameyo nuştene. Ganî ma îfade bikîn ke no beşêko kilm o. Werrekna no beş hîna derg bîyayê. Çunke zafaneyê nuştoxanê kirmanckî perwerdeyê xo bi ziwanê tirkî dîyo û goreyê sentaksê tirkî fikirênê, goreyê ney cumleyanê xo rêze kenê. Labelê tirkî û kurdkî yew malbata ziwanî ra nîyê û nê ziwanî merdimê yewbînan nîyê. Seba naye ra, sentaksê nînan zî sey pê nîyo. O semed ra ganî no beş hîna derg bîyêne. Çunke goreyê ma, mîyanê kirmancan de merdimo ke tewr baş bi kirmanckî fikirêno û ney bi kirmanckî îfade keno Malmîsanij o. O semed ra kitab de ganî nimûneyê rêzebîyayişê cumleyan hîna zêde bîyêne.

Tewr peynîya kitabî de beşê encamî esto. Nê beşî de kirmanckî û kurmanckî goreyê doneyan muqayese benê. Malmîsanij, goreyê awanîya ziwanî, bi delîlanê xo îspat keno ke kirmanckî û kurmanckî çend nêzdîyê yewbînî yê û lehçeye kurdkî yê. Serra 1838 de Ferdînand Johann Wîedeman (1805-1887) malbata ziwananê Ural-Altay ser o xebitîyayo û xususîyetê hemparê nê ziwanan tesbît kerdê. Malmîsanijî zî xususîyetê hemparê kirmanckî û kurmanckî tesbît kerdê. Xebata Malmîsanijî muhîm a çunke heta nika gramerzanan tena fikrê xo yê şexsî îfade kerdê. Labelê êdî destê ma de melumatê îlmî estê. Malmîsanijî nê melumatî kitabê xo de îfade kerde.

Kitab seba cigêrayoxan, nuştoxan, wendekaran û eleqedaranê kirmanckî ameyo nuştene. Pêşkêşîya kitabî de Malmîsanij kitabê xo wendekaranê xo rê dîyarî keno. No ma rê îşaretêk dano ke Malmîsanij qayîl o ke kitab girseyê xo bivîno û no girse kitabî ra îstîfade biko. Wendekarê ey, tena wendekarê lîsansî yan zî masterî nîyê. Her nuştox û wendekarê kirmanckî ganî kitabî ra îstîfade bikero. Yanî no kitab seba kurdan hemîne amade bîyo. No 
semed ra kitabî mîsyonêko gird girewto xo ser. Seke Malmîsanijî îfade kerdo: "Kitabê gramerê kirmanckî yê ke heta nika nusîyayê, zafane yan fekê mintiqayêk ser o yan zî fekê dewêk ser o nusîyayê. Nê tewir xebatî seba tesbîtkerdişê cîyayîya kirmanckî baş ê labelê gramer ganî bi yew lehçe û bi yew mintiqa û dewe ya sînorkerde nêmano." (Malmîsanij 2015: 18).

Bîbloyografya kitabî ra fehm beno ke Malmîsanijî zaf çimeyan ra îstîfade kerdo. Çimeyê kitabî bi îngilîzkî, almankî, kurdkî (kirmanckî, kurmanckî, sorankî, gorankî) yê. No hal qîymetê kitabî zêdneno. Kitab de 230 hebî cêrenotî estê. Nê cêrenotan de agahdarîyê zaf balkêşî estê. Malmîsanijî nê cêrenotî ge-ge sey ferhengê etîmolojî xebitnayê. Çunke seba îspatkerdişê teze xo kokê çekuye rê îşaret kerdene ûsulêko îlmî yo. Vateyo verên di rîpelî yo û seba kirmanckî agahdarîyanê başan dano. Qapaxê kitabî zaf bêreng mendo. Werrekna hîna rengin bîyayê. 